\title{
Sobre ensino, aprendizagem e resistência na aula de Filosofia do Ensino Médio ${ }^{1}$
}

Elisete M. Tomazetti ${ }^{2}$

\section{Resumo}

Este texto traz algumas reflexões que foram produzidas a partir da interação com professores e futuros professores de Filosofia do Ensino Médio. Procura problematizar os discursos por eles produzidos, os quais indicam a falta de sentido e a impossibilidade de realizarem práticas docentes que efetivem o envolvimento do aluno com a atividade de pensar filosoficamente. Toma como referência o conceito de resistência, de Michel Foucault.

\section{Primeiras aproximações}

Na ordem da instituição escolar, considera-se que o conhecimento deve ser ensinado, esteja o aluno interessado ou não; deseje ou não aprender. O professor tem a tarefa de ensinar ao aluno, que “talvez” aprenda, já que pode haver ensino sem aprendizagem, assim como pode o aluno aprender sem o ensino do professor. O objeto desse ensino é a herança cultural acumulada, que deve ser repassada às gerações mais jovens, sob pena de ser esquecido o passado e a tradição. Essa herança foi sendo transformada em disciplinas e, após ter passado por um processo de seleção e transposição, foi catalogada como currículo.

O aluno foi sendo constituído como aquele sujeito que se coloca em uma posição de espera em relação ao que deverá fazer, ouvir, ler, estudar e responder ao professor. A escola moderna constituiu-se, então, como um lugar para o qual crianças e jovens são enviados ano após ano para serem transformados em alunos e disciplinados naquilo que a sociedade definiu como necessário para a formação de seus cidadãos. Essa escola, ao longo do tempo, produziu subjetividades acopladas a um tipo-ideal moral (Jorge Ramos do Ó, 2007, p. 39) definido pelo discurso pedagógico, estatal, bem como pelas práticas sociais. Esta subjetivação constitui sujeitos para a máquina social vigente. Por sua vez, o professor exerce seu ofício, interrogando apenas aquilo para o que já tem respostas em seu caderno, e a escola vai delimitando, então, para alunos e professores, sobre o que efetivamente significa pensar.

Com o recente retorno da Filosofia como disciplina obrigatória do currículo do Ensino Médio brasileiro ${ }^{3}$, muito tem sido dito e escrito por pesquisadores da área, professores e futuros professores de Filosofia, no sentido de alertar para que essa volta signifique de fato algo novo e com valor para a escola, professores, alunos e sociedade. Há, em muitos casos, uma idealização de que a disciplina Filosofia possa resolver ou amenizar os problemas que 
ocorrem na escola, ajudando o aluno a construir um pensamento crítico sobre si e sobre seu mundo, transformando-o em um verdadeiro cidadão. Considera-se que sua presença na escola possa representar a ruptura com a velha escola e com as velhas formas de "relacionar-se com o conhecimento e com a cultura” (Jódar \& Gómez, 2004, p. 142).

No entanto, considero que é bem mais árduo o trabalho de professores e alunos na e com a aula de Filosofia na escola. Esse trabalho depende dos jogos de poder, de saber e de verdades que são ali constituídos, para possibilitar que a Filosofia na escola possa produzir algo da ordem da diferença. O professor que se propõe a exercer esse ofício precisa, antes de tudo, como nos diz Foucault, adestrar-se a si mesmo. “Apenas se emancipado, exercitado em si mesmo, o educador pode estar apto para um processo de subjetivação que insista em que cada um eduque-se a si mesmo" (Gallo \& Veiga-Neto, 2007, p. 25).

A escola pública contemporânea tem tentado manter um sentido, ainda moderno [qual é o sentido de “moderno” aqui? Explique em nota se você estiver usando “moderno” em oposição a "pós-moderno”], valendo-se da transmissão dos saberes pelo professor, da escuta do aluno e, ainda, preponderantemente, do uso do quadro, do giz, do texto escrito no livro didático, tentando recusar, sem muito êxito, as novas configurações das culturas juvenis e das nossas condições de existência. Conforme Fischer (2007, p. 291), tais condições têm produzido alterações no que diz respeito às "nossas experiências com os saberes, às trocas com os outros, às formas de inscrever-nos no social, de escrever, de falar, de pensar o mundo e a nós mesmos”.

Nessa vida escolar, a filosofia se insere, em meu ponto de vista, padecendo das mesmas dificuldades e desafios de todas as outras disciplinas escolares, ou seja, produzindo, também, um disciplinamento, que é próprio do processo de escolarização. Seus professores dão sinais de assumir uma posição de incapacidade de resistir aos dispositivos que produzem o não-sentido da escola e de seus saberes para o aluno. Se, para alguns desavisados românticos, a filosofia poderia salvar a educação escolar, para outros, sabedores da crise pela qual passa essa mesma escola, a qual tem sido imersa em um discurso que promove um outro tipo-ideal moral exigido pelo século XXI, o que é ressaltado é a impossibilidade de viabilizar formas de resistência que encaminhem para transformações. Nessa escola, então, não se produziria nenhuma experiência de sentido. Nessa perspectiva, são pontuais as palavras de Gontijo \& Valadão:

Procuramos, dessa forma, pensar como, e em que medida, ações singulares, políticas e filosóficas, localizadas, frágeis, porém latentes, afirmam o que 
muito apropriadamente Badiou chama de o infinito na experiência, ou seja, "há algo possível a se fazer, ali mesmo onde só há reclamações de impossibilidade”. (Gontijo \&Valadão, 2004, p. 289)

“Há algo possível a se fazer, ali mesmo onde só há reclamações de impossibilidade”? Quando adentramos nas produções sobre ensino de Filosofia no Brasil, uma constatação que aparece muito frequentemente é o destaque para as dificuldades do exercício do pensamento filosófico em sala de aula. É sempre manifesta a ideia de que os objetivos do ensino da disciplina são muito nobres, valiosos, porém a realidade das escolas públicas e de seus alunos é muito difícil, havendo uma distância muito grande entre o que se almeja e o que se tem efetivamente para a realização desses objetivos. No caso dos alunos, considero importante retomar, neste momento, uma fala do professor Celso Favaretto, referindo-se às dificuldades dos alunos para acessar o mundo filosófico. Destaco o uso da expressão dificuldades e não impossibilidades, pois se trata, para Favaretto, de encontrar formas de produzir saídas para esse quadro problemático da educação escolar brasileira, no qual se insere a disciplina Filosofia.

Se, a princípio, os interesses estão fixados, dada a homogeneização efetuada na cultura, o trabalho educativo de emancipação, que se espera da filosofia, está em inscrever, pragmaticamente, na sala de aula, acima de tudo, na sala de aula, tais processos fundamentais do processamento filosófico. (Favaretto, 2004, p. 47)

Essa homogeneização da cultura, que fixa os interesses e produz nos jovens o distanciamento de certos questionamentos importantes para suas vidas, que os impele ao consumismo e a um ver e pensar que muitas vezes parece corresponder à mesma atividade cognitiva, pode ser compreendida como sendo um dispositivo operado pela sociedade de controle $^{4}$. Nesse caso, uma ideia que daí pode surgir é a de que os alunos contemporâneos estão, por isso, incapacitados para a aula de Filosofia e fadados à impossibilidade de experimentar outras formas de pensamento sobre si e sobre mundo. Estariam, portanto, incapacitados para o exercício do pensamento filosófico.

Retomando a questão que abre este item, considero que, no lugar do discurso da impossibilidade, é preciso constituir o discurso da resistência no espaço escolar, por parte 
tanto do aluno quanto do professor. Se não for possível defender essa ideia, creio também ser difícil defender a relevância da Filosofia no currículo escolar.

Todavia, constato em conversas com professores e futuros professores de filosofia, seja informalmente, seja através de entrevistas, o retorno do discurso da impossibilidade de experimentar algo diferente na aula e um discurso da falta. É como se a escola, a sala de aula e o currículo fossem considerados uma caixa blindada, em cujo interior apenas se recitam versos prontos e uma oratória já ensaiada e da qual é impossível fugir, conseguindo-se, no máximo, bater-se, sem sucesso, contra suas paredes de aço. Certamente que reconhecer a caixa é importante, porém mais ainda é compreender que sua estrutura, o material de que é feita, tem-se modificado ao longo do tempo, e dentro dessa caixa ocorrem jogos de poder e de saber que permitem ações e reações.

\section{Pensando na maquinaria escolar e na aula de Filosofia}

A expressão maquinaria escolar não é nova e está sustentada nas ideias de Foucault acerca dos processos de disciplinamento instaurados por diferentes instituições sociais na modernidade ${ }^{5}$. Considera-se a escola como uma máquina na qual entram crianças e jovens para receberem uma formação que os transformará em cidadãos legítimos da sociedade. Seguindo esse raciocínio, uma questão importante hoje a ser enfrentada, me parece, diz respeito, primeiro, a como essa máquina-caixa tem funcionado e, segundo, ao tipo de sujeito que sai dela. Talvez, a partir dessa analogia da máquina-caixa, possamos pensar que hoje ela não pode ser considerada tão indestrutível, pois suas paredes têm apresentado desgastes e rachaduras que impedem a sua completa definição como caixa, e em seu interior não vige mais uma estrutura tão ordenada, clara e funcional como outrora.

É freqüente professores de Filosofia - não só eles certamente - reclamarem de seus alunos e da estrutura escolar. Dos alunos, porque eles são muitos, de diferentes classes sociais, com diferente capital cultural e trazendo suas próprias culturas juvenis, seu jeito de ser e estar como jovem contemporâneo. Reclamam da escola porque ela não seleciona eficazmente aqueles que podem adentrar na escola, os filhos bem nascidos da sociedade. Dando essa permissão que amplia o número e os tipos de sujeitos a fazerem parte da escola, esta não consegue manter a parede que separa e exclui os despossuídos, os inaptos.

Por sua vez, o discurso da inclusão, instaurado com sucesso, reforça as ideias de que todos têm direito à educação, que a escola deve receber a todos - tenham eles os "déficits ou problemas” que tiverem, seu lugar é na escola, e não fora dela. Por outro lado, a estrutura 
escolar que estava adaptada para receber aquele aluno bem nascido e com capital cultural compatível, valendo-se de alguns artefatos e tecnologias tradicionais como o quadro, o giz e o livro, por força das novas configurações contemporâneas, vê-se obrigada a incorporar em seu interior um novo conjunto de artefatos e tecnologias, como computadores, televisão, vídeo, procurando adaptar-se aos novos tempos.

Lentamente, as paredes da máquina-caixa parecem ceder, deixando entrar o “fora”, pois, como dizem Negri \& Hardt (2006, p. 206), "na passagem do moderno ao pós-moderno, e do imperialismo para o Império, é cada vez menor a distinção entre o dentro e o fora”. A hegemonia da sociedade disciplinar desfaz-se e entra em cena a sociedade de controle; mesclam-se diferentes dispositivos, sutis e aparentemente democráticos, que propõem a produção de sujeitos aptos a viverem no século XXI, na escola e fora dela.

No "fora" da escola, as formas de disciplinamento e controle, as quais Favaretto designa como homogeneização, produzem aquele aluno que o professor chama de alienado, desinteressado, distante da leitura do livro e das questões julgadas importantes para a sua vida, entre elas o questionamento filosófico. Em uma determinada perspectiva, poderia afirmar que a aula de Filosofia deveria assumir, então, o papel de salvar esses alunos e provocar-lhes a consciência crítica. A escola e a aula de Filosofia protegeriam os alunos de tais formas de submissão e, ao mesmo tempo, atuariam eficazmente como antídoto ao disciplinamento e controle produzido no “fora”. Uma outra perspectiva, considerada derrotista, entretanto, concebe a máquina-caixa como sendo gerenciada de fora, impossibilitando qualquer superação dessa realidade desde seu interior. Durante as décadas de 1970, 1980 e parte de 1990 do século XX, esta narrativa constituía o discurso pedagógico denominado crítico, que demonstrava forte poder de convencimento.

Tais perspectivas, considero, não contemplam a complexidade deste nosso tempo, que tem produzido modificações em nossos modos de existência. Por isso, procurarei defender aqui a ideia de que o discurso de atuais e futuros professores de Filosofia, com os quais convivo, está centrado ainda numa perspectiva moderna e crítica, caindo desta forma em becos sem saída, em labirintos argumentativos, que impedem a produção de outras práticas no interior da escola e nos espaços de formação superior.

\section{Sobre os labirintos argumentativos dos professores de Filosofia}

A impossibilidade de tornar a aula de Filosofia um espaço no qual ocorre a experiência do pensamento filosófico é apontada pelos professores e justificada na falta de vontade dos 
alunos para lerem e escreverem, no distanciamento cada vez maior desses jovens de atitudes consideradas cidadãs, civilizadas e vinculadas ao mundo da cultura letrada.

A seguir, apresento algumas falas de professores de Filosofia de escolas públicas de Ensino Médio da cidade de Santa Maria, Rio Grande do Sul, constituídas a partir de entrevistas semiestruturadas, no contexto da pesquisa Filosofia, Cultura Juvenil e Ensino Médio ${ }^{6}$.

É... O que me desestimula é a falta de cultura filosófica, digamos, na nossa escola. Então quer dizer, tu pega alunos que nunca foram trabalhados né, para uma reflexão, tu tem alunos mecânicos, que querem o conteúdo, que querem fazer uma prova pra ter uma nota. E aí isso aí que é difícil. (professor 1)

Falta de “cultura filosófica” e, logo, de um hábito reflexivo por parte dos alunos. (professor 2)

No início não foi fácil. Eles não têm essa visão, eles têm preguiça de pensar. Eles não sabiam nem o que era uma crítica. Os filósofos para eles eram coisas diferentes (...). Ele tem preguiça de ler. No início foi complicado, mas depois eles foram compreendendo e entendendo, não foi fácil lidar com o jovem e a filosofia. (professor 5)

Ah, falta de condições, não tem como competir, não tem como competir, não tem. Eu tenho duas aulas por semana na primeira série e uma por semana de filosofia política. (professor 7)

Enquanto que também por outro lado o que me desestimula é justamente essa, às vezes, banalização e esse pouco sentido da existência humana, das questões de fundo, de você ter uma reflexão mais sobre qual é o papel que cada um de nós ocupa e tal. Então tem certas coisas assim que a gente fala assim, o que mais incomoda no adolescente, é sua - na verdade é o “aborrecente”, sabe aquela sua coisa assim de superficialidade, mas a gente tem que entender que talvez esse também seja o lado bom, né, porque levar as coisas numa coisa, assim, mais leve permite eles irem mais longe, né, e não ter preconceito e aceitar novos desafios (...) Então, por um lado, assim, é meio contraditório, por 
um lado tem essa possibilidade de você vivenciar o novo, mas ao mesmo tempo você se contradiz porque a juventude, às vezes valoriza coisas que pra você é extremamente... Que deveriam se interessar por coisas mais úteis, não mais úteis no sentido de utilitário, mas mais sérias, de maior importância. Também temos outras coisas, assim, que também, às vezes tu nota, assim: os valores que muitas vezes a juventude (...) traz muitas vezes das famílias - e isso é uma coisa importante - e às vezes também isso prejudica sua própria formação de ser humano, então, ao longo da vida. Então, essas coisas assim, ao mesmo tempo é um desafio tu conviver com isso, mas ao mesmo tempo você nota que também mesmo aquilo que nos - Fernando Pessoa fala um pouco aquilo - mesmo aquilo que nos ama nos aprisiona, nos oprime e tal. É uma situação... Então, conviver com adolescente é bem isso, né, é uma contradição em si. Professor? (professor 6)

Os professores reclamam que os alunos não têm interesse pela Filosofia, não têm cultura filosófica, são imediatistas, não gostam de ler, têm dificuldade de concentração, ou seja, são, em grande parte, alfabetizados, mas não “letrados”. São “aborrecentes”. É considerado difícil e quase impossível, na concepção do docente, ensinar Filosofia, desenvolver nos alunos a reflexão e o pensamento crítico nessa escola pública brasileira, pois nela se agregam, ainda, as situações de violência, de falta - de estrutura e de equipamentos, de salas de aula agradáveis, de espaços com computador, projetor de multimídia, televisão e com bibliotecas fartas e atraentes aos alunos.

Seguindo os argumentos acima, são identificados problemas nos alunos e na escola. Nos alunos, porque não querem estudar e carregam déficits importantes que comprometem seu contato com a Filosofia. Na escola, porque esta não dispõe de infraestrutura razoável para o bom andamento das aulas, nem tampouco de uma cultura organizacional e pedagógica que defina e mantenha claramente os objetivos da escolarização para produzir um disciplinamento eficaz.

Quando são os futuros professores, os estagiários de Filosofia, a se referirem à aula de Filosofia nessa escola, as mesmas reclamações retornam. Nesse caso, estando ainda inseridos num curso de formação superior, em contato com a tradição filosófica e com os grandes problemas da área, a tarefa de ensinar alunos na escola é considerada ainda mais difícil e desalentadora. A saída, para alguns, ocorre pela adequação a essa cultura escolar, “passando” 
o conteúdo que foi aprendido durante sua formação universitária, lançando mão de sanções cada vez mais fortes e aderindo ingenuamente aos jogos que são vividos na escola.

Retorna aqui a questão destacada anteriormente. Os problemas elencados pelos professores, nos fragmentos das entrevistas, podem ser indícios de seu 'despreparo' ou de suas dificuldades em aceitar lidar com esse público e com essa instituição. Pode-se inferir que esses professores não estão aptos, não foram preparados ou não querem trabalhar com a realidade do aluno "aborrecente". Nesse caso, considero um fator importante para o desenvolvimento do ofício de professor a habilidade e o gosto de fazê-lo. Poderia supor que tudo se passou muito bem no processo formativo dos futuros professores até eles chegarem na escola e então se darem conta de que a 'receita', os modelos que receberam não se encaixam, não servem. O problema situa-se, então, no entendimento equivocado de que, em seu curso de formação, foi apresentado o caminho, a forma, o jeito, a metodologia correta e prenhe de sucesso, e agora, na prática docente, tais dispositivos não se adaptam à situação vivida.

Para ultrapassar esse entendimento, considero que seria mais eficiente se pensar que a formação docente deve ser desenvolvida a partir daquela ideia que Foucault e Deleuze utilizam ao referirem-se aos conceitos, ou seja, a ideia da caixa de ferramentas ${ }^{7}$. Penso que saídas inventivas para a aula de Filosofia na escola pública passam por uma formação que possibilita aos futuros professores saberem que apenas lhes resta, em sua saída para o mundo da escola, uma caixa com algumas ferramentas e que, de resto, eles terão mesmo é que criar/inventar e, principalmente, resistir à tentação de quererem o dado como ordem que garante sua tranqüilidade pedagógico-filosófica.

Por outro lado, é preciso que os professores consigam desnaturalizar a ideia de que os alunos são e agem de forma resistente ou indiferente à aula de Filosofia, mas não só a ela, porque assim desejam. Na verdade, eles foram sendo produzidos como alunos por determinadas práticas discursivas e não-discursivas ao longo de sua existência dentro e fora da escola. A questão é conseguir problematizar tais práticas de forma a fugir do recurso à culpa, e tentar encontrar algumas brechas que possam viabilizar algo de diferente que, mesmo na sua suposta pequenez, é da ordem da criação e da resistência.

Entretanto, no geral, o discurso dos professores de Filosofia mantém-se preso à ordem que se estabelece no próprio funcionamento do currículo escolar. É um sintoma produzido pelo modo de operar da própria maquinaria, seja da formação de professores de Filosofia, seja do modo como a sociedade contemporânea engendra o funcionamento das instituições e, neste caso em particular, da escola, e principalmente da recepção à Filosofia. 
Designo essa forma de referir-se aos alunos e à escola contemporânea como o discurso da falta. Esse discurso tem sido freqüente, como já afirmei. O lugar de onde se “olha” e se narra a escola e os alunos é um lugar da verdade, das certezas, dos objetivos claros e da isenção daquele que produz tal discurso. É um discurso que resguarda uma metanarrativa na qual a escola é a instituição que produz a emancipação dos sujeitos alunos, desde que cheguem nela com um capital cultural adequado. Esse discurso, ao se manter, instaura a ordem do impossível, sustentado pelas reclamações, pelas dificuldades, pela saudade de um outro aluno, com outras características. Diante disso o que resta é seguir reafirmando, tentando produzir, dentro dessa cultura escolar, o que já não poderia mais subsistir. Mantémse a escola que está aí. Insere-se a Filosofia no currículo escolar para adequar-se ao instituído e reforçar o coro das lamentações de professores e alunos.

A vida quotidiana da escola parece, paradoxalmente, reproduzir dispositivos de poder e de resistência cuja lógica se reconstitui à medida que se reconfiguram suas estratégias e suas manifestações em contextos diferentes. A arquitetura e a rotina da escola, em diferentes formas, assumidas segundo os respectivos ambientes históricos e socioculturais, parecem incorporar normas e procedimentos combatidos em sucessivas tentativas de reforma do sistema escolar, mesmo com o impacto de profundas revoluções sociais. Todavia, ambivalentemente, nas fissuras das paredes divisórias e nos acasos que convulsionam as rotinas escolares, relações vivas e diferenciadas tentam emergir e vingar a qualquer momento. (Fleuri, 2008, p. 474)

\section{Escola, aula de Filosofia e Resistência}

Em um texto intitulado Revolução, revolta e resistência: a sabedoria dos surfistas, Charles Feitosa (2007) faz um belo percurso por entre estes conceitos. Refere-se à revolução, valendo-se de Hannah Arendt, para a qual, no sentido moderno, revolução "não envolve simplesmente mudanças, mas sim acontecimentos que pretendem instaurar um novo começo” (2007, p. 19). Revolta é um termo cujo caráter negativo indica "rejeição da autoridade, oposição a um poder, desvio de uma crença etc. (...) dizer não a todo custo, contra tudo e contra todos” (2007, p. 22). E, por fim, resistência, que, a partir de Nietzsche e Deleuze, "tem um outro significado para a palavra resistir, que não seja mais um resistir contra algo, mas um re-insistir. Resistência como uma forma especial de enfrentar o poder, de dizer não e sim, de agir conforme a liberdade, de lidar com a morte e com os muros da política” (2007, p. 26). 
Seguindo Feitosa, considero que o conceito de resistência pode nos ajudar a pensar saídas dos labirintos argumentativos em que têm se colocado professores e futuros professores de Filosofia do Ensino Médio. Escapar ao discurso da falta, da impossibilidade, mas também ao discurso da salvação da escola e do aluno pela aula de Filosofia (este não tão presente contemporaneamente).

Este conceito também remete à obra Império, de Negri \& Hardt (2006, p. 206), na qual os autores indicam que "no espaço liso do Império, não há lugar de poder - ele está ao mesmo tempo em todos os lugares e em lugar nenhum”. Se a distinção entre o dentro e o fora, em termos de espaço privado e público, se esvai e se o mercado capitalista se impõe a tudo e a todos como uma inclusão onipotente, de qual lugar poderíamos produzir a revolução ou a revolta? Importante relembrar a compreensão de Império, oferecida por Negri \& Hardt:

Em contraste com o imperialismo, o Império não estabelece um centro territorial de poder, nem se baseia em fronteiras ou barreiras fixas. É um aparelho de descentralização e desterritorialização do geral que incorpora gradualmente o mundo inteiro dentro de suas fronteiras abertas e em expansão. (2006, p. 12)

É pensando na ordem mundial que nos enlaça - o Império - que a tomada do conceito de resistência torna-se vital para a continuidade de nosso envolvimento com as questões de ensino, de dentro das instituições escola e universidade. Deixadas para trás as metanarrativas que indicavam a possibilidade de revolução e revolta para fazer surgir outra sociedade, outro espaço público e outra escola, hoje a pergunta é: como podemos resistir dentro desta grande caixa social chamada Império, da qual não saímos, pois não há o fora?

Valho-me, então, das palavras de Feitosa, que indica a possibilidade de pensarmos hoje, na sociedade de controle, sobre as questões de poder, dominação e falta de saídas:

Se o modelo da revolução é a órbita dos planetas, a torrente que lava, a onda que tudo arrasa; se a retórica da revolta envolve um não que a tudo arrasa, um não que se volta contra a própria condição humana, como se o homem socasse as ondas do mar, então a imagem mais apropriada para o gesto de resistência é a do surfista, aquele que nem luta desarvoradamente nem se deixa levar como um graveto, mas que tem a sabedoria paradoxal de respeitar e aproveitar a 
força, a velocidade e a intensidade das ondas. O surfista incorpora a imagem do filósofo do amor fati, aquele que tem a capacidade de dizer não para os impasses tradicionais da revolução e da revolta, mas também sabe dizer sim para as surpresas do acaso, condição de possibilidade do gesto de criação na arte e na vida. (Feitosa, 2007, p. 28-29)

Para Deleuze, retomando Foucault, a sociedade disciplinar lentamente foi se transformando na sociedade de controle, na qual este (o controle) promove uma dominação sem clausura. A esta sociedade, organização política e econômica, Negri \& Hardt chamam Império. Nesta sociedade está a escola com sua aula de Filosofia e cabe pensar em agir como o surfista que resiste, dizendo sim e não, e aproveitar os próprios dispositivos usados pela escola para fazer diferente, para criar outras aulas de Filosofia. Qual é a onda do momento na educação brasileira? Retomando afirmações já feitas nas páginas iniciais deste texto, poderia indicar, como a onda na qual temos que surfar como professores e formadores de futuros professores, a ideia de crise e da falta de tudo, nos alunos e na escola, por exemplo. Indo mais além nessa caracterização, diria, com Feitosa (2007, p. 29), que o nosso niilismo brasileiro se apresenta em formas específicas, como "o tédio, a supervalorização da beleza física, ou ainda a indiferença generalizada em relação aos muros da política”.

Ao explicitar o que considera relações de poder, Foucault indica as formas de resistência que nela ocorrem. Afirma que o principal objetivo de tais lutas "é atacar, não tanto 'tal ou tal' instituição de poder ou grupo ou elite ou classe, mas, antes, uma técnica, uma forma de poder. (...) É uma forma de poder que faz dos indivíduos sujeitos” (Foucault, 1995, p. 235). O fato de a escola, ao longo do tempo, ter produzido um tipo de sujeito-aluno não impediu que nela se efetivassem processos de resistência, que encaminharam certamente para a existência de conflitos, “indisciplina” e impasses em seu interior. O exercício do poder é sempre relação que exige que "o outro (aquele sobre o qual ela se exerce) seja inteiramente reconhecido e mantido até o fim como o sujeito da ação; que se abra, diante da relação de poder, todo um campo de respostas, reações, efeitos, invenções possíveis” (1995, p. 243).

\section{Finalizando}

Muitas vezes, meus alunos, que estão realizando seu estágio de Filosofia nas escolas públicas de Santa Maria, RS, dizem que é muito difícil efetivar práticas que encaminhem para o envolvimento e implicação de seus alunos com a aula; que não conseguem fazer diferente 
daquilo que criticaram em outros professores e estão a um passo de reproduzir as mesmas práticas que abominavam. Nesse momento lhes proponho que perguntem como a escola funciona. Como sua aula funciona? A partir destas perguntas, podem, talvez, pensar e produzir pequenas "brechas" e "rachaduras" que possam construir a aula como acontecimento, fugindo das armadilhas que sustentam as práticas discursivas e nãodiscursivas que permeiam o cotidiano da escola.

Se estamos de acordo que transformações profundas estão alterando nossos modos de existência, não é razoável deixar de considerar o quanto tais transformações estão afetando fortemente a instituição escolar, a ponto de exigir de nós, envolvidos com esta instituição, um exercício e uma prática que a tome como central e emergencial.

Como afirma Veiga-Neto (2008, p. 34),

boa parte da subjetivação operada na e pela escola - uma subjetivação durante muito tempo realizada preponderantemente pelo poder e pelas práticas disciplinares - ou se deslocou para o espaço social mais amplo ou, mesmo ainda ocorrendo no espaço escolar, deixou de contar com aquele tipo de poder e com aquelas práticas (como tecnologias) para a fabricação de sujeitos.

Os alunos da escola de ensino médio não estão condicionados à passividade, à aceitação de tudo ou à recusa e indiferença a tudo. O professor também não está submetido inexoravelmente às políticas públicas, às exigências que lhe são encaminhadas e à aceitação da cultura escolar instituída. As relações de poder constituem um "campo de respostas, reações, efeitos, invenções possíveis” (Veiga-Neto, 2008, p. 243), e podem, sim, romper com a ordem do impossível.

\section{Referências}

DELEUZE, Gilles. Post-scriptum sobre as sociedades de controle. In: DELEUZE, Gilles. Conversações. São Paulo: Editora 34, 1992. p. 219-226.

FAVARETTO, Celso. Filosofia, ensino e cultura. In: KOHAN, Walter (Org.) Filosofia: caminhos para seu ensino. Rio de Janeiro: DP\&A, 2004. p. 43-53.

FEITOSA, Charles. Revolução, revolta e resistência: a sabedoria dos surfistas. In: LINS, Daniel (Org.). Nietzsche, Deleuze, arte, resistência. Rio de Janeiro: Forense Universitária; Fortaleza: Fundação de Cultura, Esportes e Turismo, 2007. p. 17-31. 
FISCHER, Rosa M. B. Mídia, máquinas de imagens e práticas pedagógicas. Revista Brasileira de Educação, v. 35, 2007. p. 290-299

FLEURI, Reinaldo Matias. Rebeldia e democracia na escola. Revista Brasileira de Educação, v. 13, n. 39, Rio de Janeiro, Set./Dez. 2008. p.470-482.

FOUCAULT, Michel. O sujeito e o poder. In: DREYFUS, Hubert L.; RABINOW, Paul. Michel Foucault: uma trajetória filosófica: para além do estruturalismo e da hermenêutica. Rio de Janeiro: Forense Universitária, 1995. p. 231-249.

FOUCAULT, Michel; DELEUZE, Gilles. Os intelectuais e o poder. In: FOUCAULT, Michel. Microfísica do poder. Rio de Janeiro: Graal, 1979. p. 69-78.

GALLO, Silvio; VEIGA-NETO, Alfredo. Ensaio para uma filosofia da educação. Revista Educação - Especial Biblioteca do Professor - Foucault pensa a educação, v. 3, São Paulo, Editora Segmento, ano, 2007. p.16-25.

GONTIJO, Pedro; VALADÃO, Erasmo Baltazar. Ensino de filosofia no ensino médio nas escolas públicas no Distrito Federal: história, práticas e sentidos em construção. Cadernos CEDES, v. 24, n. 64, Campinas, Set./Dec. 2004. p. 285-303.

JÓDAR, Francisco; GÓMEZ, Lucia. Experimentar o presente: sobre a conformação de novas identidades. Revista Educação \& Realidade - Dossiê Michel Foucault, v. 29, n. 1, Jan./Jun. 2004, Porto Alegre. p. 139-153.

NEGRI, Antonio; HARDT, Michael. Império. 8. ed. Rio de Janeiro: Record, 2006.

RAMOS do Ó, Jorge. O governo do aluno na modernidade. Revista Educação - Especial Biblioteca do Professor - Foucault pensa a educação, v. 3, São Paulo, Editora Segmento, ano, 2007. p.36-45.

VARELA, Julia; URIA, Fernando. Arqueologia de la escuela. Madrid: La Piqueta, 1991. VEIGA-NETO, Alfredo. Dominação, violência, poder e educação escolar em tempos de Império. In: RAGO, Margareth; VEIGA-NETO, Alfredo (Org.). Figuras de Foucault. Belo Horizonte: Autêntica, 2008. p. 13-38.

\footnotetext{
${ }^{1}$ Artigo originalmente apresentado em setembro de 2009 no II Encontro Nacional do Grupo de Trabalho Filosofar e Ensinar a Filosofar da Associação Nacional de Pós-Graduação em Filosofia (ANPOF), realizado na Universidade Gama Filho, no Rio de Janeiro.

${ }^{2}$ Professora da Universidade Federal de Santa Maria (UFSM). Correio eletrônico: elisetem2@gmail.com

${ }^{3}$ Lei 11.684, assinada pelo vice-presidente da República, em junho de 2008.

${ }^{4}$ Sobre Sociedade de Controle, conferir Deleuze, Post-scriptum sobre as sociedades de controle, 1992.

${ }^{5}$ Cf. Julia Varela \& Fernando Uria. Arqueologia de la escuela, 1991.

${ }^{6}$ Esta pesquisa desenvolveu-se em várias etapas, como: entrevista a professores de Filosofia de algumas escolas públicas de Ensino Médio de Santa Maria, RS; questionários a 370 alunos; e, por fim, entrevistas coletivas com grupos de alunos. Realizou-se entre os anos de 2004 e 2009 e está sendo organizada para publicação final. Cf. Foucault \& Deleuze, 1979.
} 